\title{
Mechanical Characterization of Epoxy Polymer Concrete Containing Fly Ash
}

\author{
Raman Bedi and Nagendra Kumar Gupta
}

\author{
Department of Mechanical Engineering, National Institute of Technology, Jalandhar, India
}

\begin{abstract}
Polymer concrete is a composite material made of aggregates and polymeric resin as a binder. The applications of polymer concrete is limited not only to the domain of civil engineering but it has got inroads in to structural applications in Machine tool structures. Till date no standard mix design procedures are available for polymer concrete systems. In this research, Polymer concrete samples were made using epoxy resin as a binder, fly ash as a filler and marble waste as aggregate. The various mix proportions were developed using concept of mixture design of experiments. Compressive and flexural strength was evaluated for each composition of polymer concrete thus obtained. The effect of variables such as epoxy resin, fly ash and aggregates were analyzed. An optimum mix composition has been developed using the regression equations. The coefficient of correlation (R-Square) between the experimental value and predicted value was found to be high near about one proving the fitness of the model.
\end{abstract}

Keywords: Polymer concrete, Fly Ash, Mixture design of experiments, Compressive strength, flexural strength.

\section{INTRODUCTION}

The usual building material namely cement concrete is prepared by binding aggregate with Portland cement. Its low cost, ease of application and compressive strength are the principal reasons for its universal acceptance. In time cement concrete has been improved by adding polymeric additives and polymeric material were used for substituting partially or totally the hydraulic cement binder. Polymer concrete is a part of group of concrete that use polymer to replace cement as a binder. Polymer concrete is a composite material in which the aggregate are included in a polymer matrix. The use of polymer resin instead of Portland cement in the concrete mix improves the mechanical behaviour and durability properties [1, 2].

Polymers in concrete have received considerable attention over the past 25 years. Polymer concrete (PC) became well known in the 1970s and is used for repair, thin overlays for floors and bridges in sports arenas and stadiums, laboratories, hospitals, factories, and entrances of stores, and for precast component has been used to produce a wide range of products, including drains, underground boxes, manholes, building cladding, acid tanks and cells, shells for repairing machinery foundations, floor tile, and machine tools and bases [2].

The final characteristics of polymer concrete depend on the type and dosage of resin binder, type and amount of filler and aggregates, curing conditions,

*Address correspondence to this author at the Department of Mechanical Engineering, National Institute of Technology, Jalandhar, India;

Tel: +91-9815981054; Fax: +91-181-2690932;

E-mail: bediraman74@gmail.com silane treatment of aggregates etc. Studies on polymer concrete with different types of resin such as: epoxy resin [3, 4], polyester resin [5-9], furan resin [10, 11], poly methylmethacrylate [12] have been reported in literature. For increasing the properties of polymer concrete various fiber reinforcements are also used (glass, carbon fibers, PVA, etc.) [13-15]. Different types of fillers can be used, considering especially the industrial wastes such as fly ash, slag, micro silica, cinder $[16,17]$.

\section{MIXTURE DESIGN OF EXPERIMENTS}

Design of experiments comprises a group of statistical techniques which can be used for model building, model exploitation and optimizing multivariable systems. It is not a good practice to stick to one approach for solving all process optimization problems. Mixture design approach is the best approach for the evaluating the response of systems where input variables can be proportions of various components in a blend. The design factors in a mixture experiment are the proportions of the components of a blend and the response variables vary as a function of these proportions to optimize a mixture whose properties depend on the proportions of the component materials. In these techniques, a set of trial batches covering a chosen range of proportions for each component is set up according to established statistical procedure. Trial batches are performed and results are analyzed using standard statistical methods that each response is expressed as an algebraic function of factors. Once a response is characterized by an equation, any number of analyses is possible [3, 4, 11]. It provides a systematic approach to experimentation so that one can study a large number of variables in a 
minimum number of experimental trails. In a mixture experiment, the independent factors are proportions of different components of a blend. The fact that the proportions of the different factors must sum to 1 or $100 \%$ complicates the design as well as the analysis of mixture experiments [18].

\section{MATERIALS AND METHODS}

Polymer concrete samples were prepared in laboratory using epoxy resin GY-257 along with HY-54 hardener as a binder. Gap graded marble waste of two grades, 0.3-0.85 mm (Type-I) and 2.36-4.75mm (TypeII) was used as aggregate material. Fly ash was used as a micro filler material. The main aim of the study was to determine the effect of input variables (mixture components) on the mechanical properties of polymer concrete. The various input variables along with their range of variation are shown in Table 1. Similar range of variables is already reported in literature [3]. The polymer concrete mixes as obtained through mixture design of experiments for the chosen range are given in Table 2.

Specimens were prepared by mixing required quantities of resin with aggregates and micro filler (fly ash) thoroughly as per the proportions of Table 2. A minimum dosage, $12.5 \%$ of epoxy resin has been adopted from the workability condition and a maximum dosage of $18.9 \%$ was taken due to segregation of aggregates from resin. The fly ash content varied from 6.5 to $12.9 \%$, from the condition of workability. After complete mixing, the prepared polymer concrete slurry was used for casting specimen in the greased moulds. Specimen casting was carried out under vibration on the vibrating table, the vibration being generated using high frequency electric vibrators. Prepared sample were removed from mould and allowed for curing in

Table 1: Range of Variables and their Coded Form

\begin{tabular}{|c|c|c|c|c|c|}
\hline \multirow{2}{*}{ S.N } & \multirow{2}{*}{ Variable } & \multicolumn{2}{|c|}{ Lower limit } & \multicolumn{2}{|c|}{ Upper limit } \\
\cline { 3 - 6 } & & Coded value & $\%$ & Coded value & 1 \\
\hline \hline 1 & A, Epoxy Resin & 0 & 12.5 & 1 & 12.9 \\
\hline 2 & B, Fly ash & 0 & 6.5 & 1 & 1 \\
\hline 3 & C, Aggregate type I & 0 & 37.3 & & 1 \\
\hline 4 & D, Aggregate type II & 0 & 37.3 & & 43.7 \\
\hline
\end{tabular}

Table 2: Mixture Design Combinations for Polymer Concrete

\begin{tabular}{|c|c|c|c|c|c|c|}
\hline PC Combination & $\begin{array}{c}\text { Std } \\
\text { order }\end{array}$ & $\begin{array}{l}\text { Run } \\
\text { order }\end{array}$ & A: Epoxy Resin & B: Fly ash & C: Aggregate type I & D: Aggregate type II \\
\hline PC1 & 1 & 15 & 18.9 & 6.5 & 37.3 & 37.3 \\
\hline PC2 & 2 & 2 & 12.5 & 12.9 & 37.3 & 37.3 \\
\hline PC3 & 3 & 11 & 12.5 & 6.5 & 43.7 & 37.3 \\
\hline PC4 & 4 & 13 & 12.5 & 6.5 & 37.3 & 43.7 \\
\hline PC5 & 5 & 6 & 15.7 & 9.7 & 37.3 & 37.3 \\
\hline PC6 & 6 & 9 & 15.7 & 6.5 & 40.5 & 37.3 \\
\hline PC7 & 7 & 14 & 15.7 & 6.5 & 37.3 & 40.5 \\
\hline PC8 & 8 & 10 & 12.5 & 9.7 & 40.5 & 37.3 \\
\hline PC9 & 9 & 12 & 12.5 & 9.7 & 37.3 & 40.5 \\
\hline PC10 & 10 & 5 & 12.5 & 6.5 & 40.5 & 40.5 \\
\hline PC11 & 11 & 3 & 16.5 & 7.3 & 38.1 & 38.1 \\
\hline PC12 & 12 & 8 & 13.3 & 10.5 & 38.1 & 38.1 \\
\hline PC13 & 13 & 1 & 13.3 & 7.3 & 41.3 & 38.1 \\
\hline PC14 & 14 & 4 & 13.3 & 7.3 & 38.1 & 41.3 \\
\hline PC15 & 15 & 7 & 14.1 & 8.1 & 38.9 & 38.9 \\
\hline
\end{tabular}



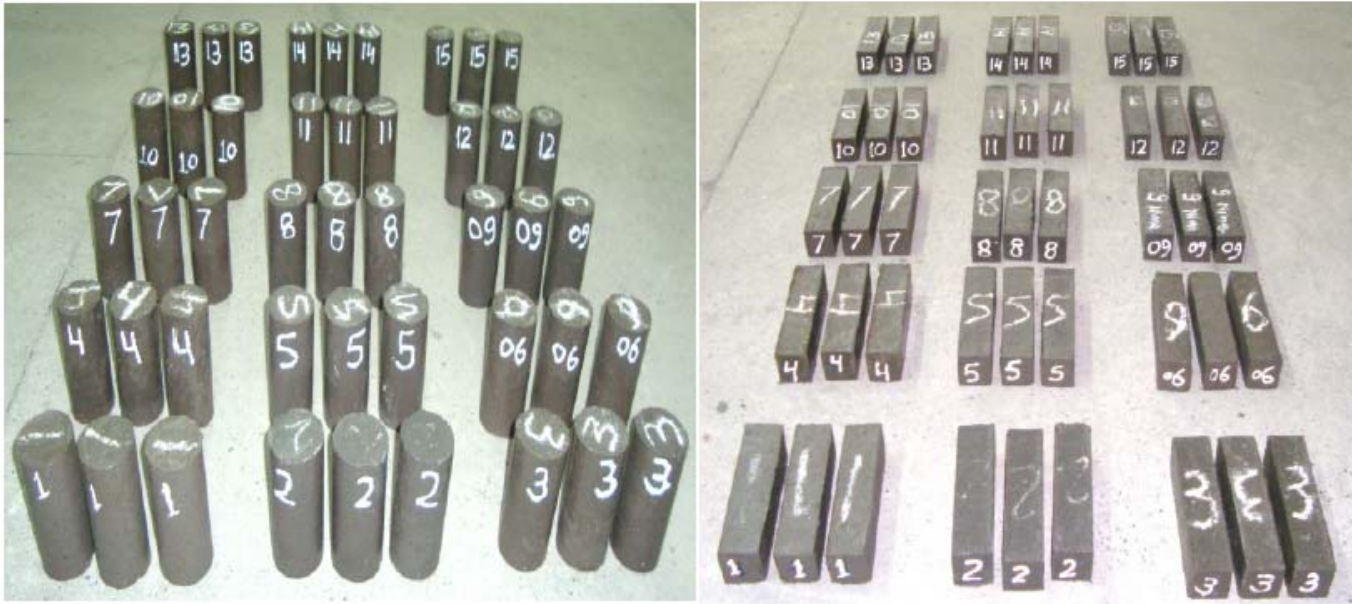

Figure 1: Compressive and flexural testing Specimens.

ambient temperature condition for seven days. The specimens used for flexural testing were prismatic of size $40 \times 40 \times 160 \mathrm{~mm}$ confirming to RILEM CPT PC-8 whereas cylindrical samples of $\mathrm{L}=100 \mathrm{~mm}$ and Diameter $=50 \mathrm{~mm}$ confirming to ASTM C $39 / \mathrm{C} 39 \mathrm{M}$ were used for compressive testing. The specimens such casted are shown in Figure 1.

For flexural testing, prismatic polymer concrete samples were tested in three point bending up to failure at the loading rate of $1 \mathrm{~mm} / \mathrm{min}$, with the span of length $100 \mathrm{~mm}$, according to RILEM CPT PCM-8. Cylinder polymer concrete specimens were tested in compression at the loading rate of $1.25 \mathrm{~mm} / \mathrm{min}$ according to ASTM C39-05 standard.

\section{RESULTS AND DISCUSSION}

For all the 15 Polymer concrete compositions types developed by using mixture design of experiments, the mechanical characteristics were experimentally determined. Table $\mathbf{3}$ displays the compressive strength of Polymer concrete samples for each run having three replicates. The average strength for each run has been reported in the table Along with standard deviation. Table 4 displays the flexural strength of Polymer

Table 3: Compressive Strength Results of PC

\begin{tabular}{|c|c|c|c|c|c|}
\hline PC Combination & $\begin{array}{l}\text { Compressive } \\
\text { strength } \\
\text { (Sample 1) }\end{array}$ & $\begin{array}{l}\text { Compressive } \\
\text { strength } \\
\text { (Sample 2) }\end{array}$ & $\begin{array}{l}\text { Compressive } \\
\text { strength } \\
\text { (Sample 3) }\end{array}$ & $\begin{array}{l}\text { Average compressive } \\
\text { strength } \\
\text { (MPa) }\end{array}$ & $\begin{array}{l}\text { Standard } \\
\text { Deviation }\end{array}$ \\
\hline PC1 & 32.58 & 32.58 & 34.11 & 33.09 & 0.88 \\
\hline PC2 & 65.67 & 62.62 & 62.62 & 63.64 & 1.76 \\
\hline PC3 & 60.07 & 53.96 & 61.60 & 58.55 & 4.04 \\
\hline PC4 & 54.98 & 59.05 & 55.49 & 56.51 & 2.22 \\
\hline PC5 & 40.22 & 51.93 & 40.73 & 44.29 & 6.62 \\
\hline PC6 & 35.64 & 47.85 & 40.22 & 41.24 & 6.17 \\
\hline PC7 & 45.82 & 37.16 & 36.15 & 39.71 & 5.32 \\
\hline PC8 & 64.15 & 65.16 & 53.96 & 61.09 & 6.20 \\
\hline PC9 & 75.35 & 62.11 & 58.04 & 65.16 & 9.05 \\
\hline PC10 & 50.40 & 51.42 & 41.75 & 47.85 & 5.31 \\
\hline PC11 & 45.82 & 40.22 & 42.15 & 42.73 & 2.84 \\
\hline PC12 & 54.98 & 51.38 & 52.36 & 52.91 & 1.87 \\
\hline PC13 & 42.45 & 41.64 & 40.71 & 41.60 & 0.87 \\
\hline PC14 & 42.11 & 42.76 & 43.24 & 42.70 & 0.57 \\
\hline PC15 & 38.87 & 40.73 & 41.27 & 40.29 & 1.26 \\
\hline
\end{tabular}


Table 4: Flexural Strength Results of PC

\begin{tabular}{|c|c|c|c|c|c|}
\hline PC Combination & $\begin{array}{c}\text { Flexural strength } \\
\text { Sample } 1\end{array}$ & $\begin{array}{c}\text { Flexural strength } \\
\text { Sample } 2\end{array}$ & $\begin{array}{c}\text { Flexural strength } \\
\text { Sample } 3\end{array}$ & $\begin{array}{c}\text { Average } \\
\text { Flexural strength } \\
\text { (MPa) }\end{array}$ & $\begin{array}{l}\text { Standard } \\
\text { deviation }\end{array}$ \\
\hline PC1 & 18.29 & 15.59 & 18.16 & 17.35 & 1.52 \\
\hline PC2 & 22.65 & 25.33 & 22.86 & 23.61 & 1.49 \\
\hline PC3 & 21.78 & 21.06 & 19.72 & 20.85 & 1.04 \\
\hline PC4 & 18.94 & 19.03 & 19.21 & 19.06 & 0.14 \\
\hline PC5 & 14.41 & 15.91 & 14.22 & 14.85 & 0.93 \\
\hline PC6 & 14.20 & 13.51 & 15.20 & 14.31 & 0.85 \\
\hline PC7 & 24.03 & 15.48 & 15.15 & 18.22 & 5.03 \\
\hline PC8 & 21.91 & 23.24 & 20.58 & 21.91 & 1.33 \\
\hline PC9 & 22.04 & 22.80 & 21.29 & 22.05 & 0.76 \\
\hline PC10 & 16.67 & 17.63 & 18.76 & 17.69 & 1.042 \\
\hline PC11 & 18.16 & 17.95 & 16.94 & 17.68 & 0.65 \\
\hline PC12 & 18.87 & 17.58 & 18.98 & 18.48 & 0.78 \\
\hline PC13 & 13.85 & 14.96 & 14.53 & 14.45 & 0.56 \\
\hline PC14 & 16.08 & 15.43 & 18.50 & 16.67 & 1.62 \\
\hline PC15 & 15.65 & 15.72 & 15.04 & 15.47 & 0.37 \\
\hline
\end{tabular}

concrete samples for each run having three replicates. The average strength for each run has been reported in the table along with standard deviation. A cursory look at the results reveals that maximum compressive strength and Flexural strength is obtained for PC-9 and PC-2 combinations respectively. Both these PC combinations contain $12.5 \%$ resin, i.e. the least resin content in these experiments. Figures 2 and $\mathbf{3}$ show some representative load/deflection curves for compressive and flexural testing respectively. It is observed that polymer concrete specimens exhibit almost brittle failure after the maximum load.

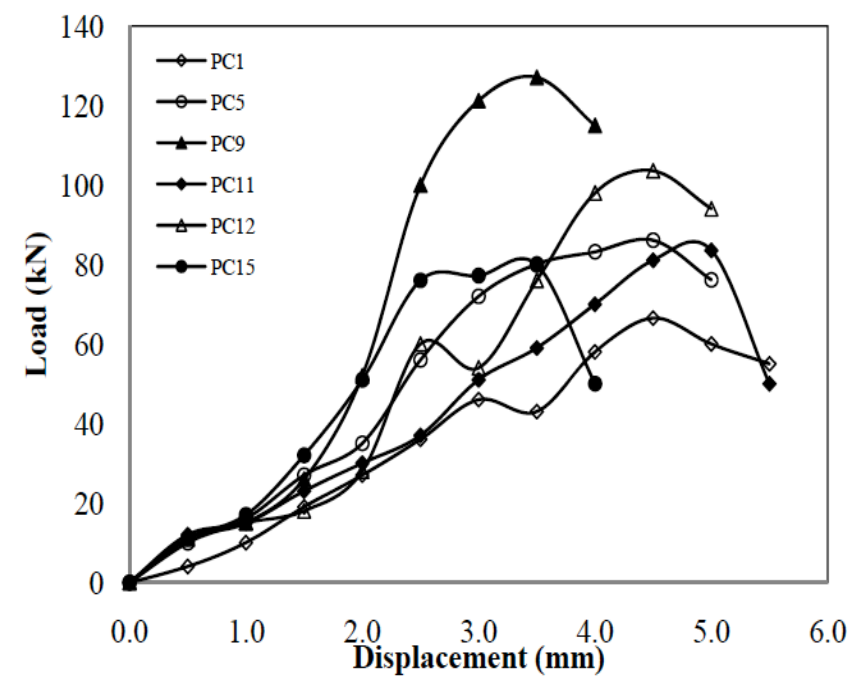

Figure 2: Load-Deformation curves in compression.

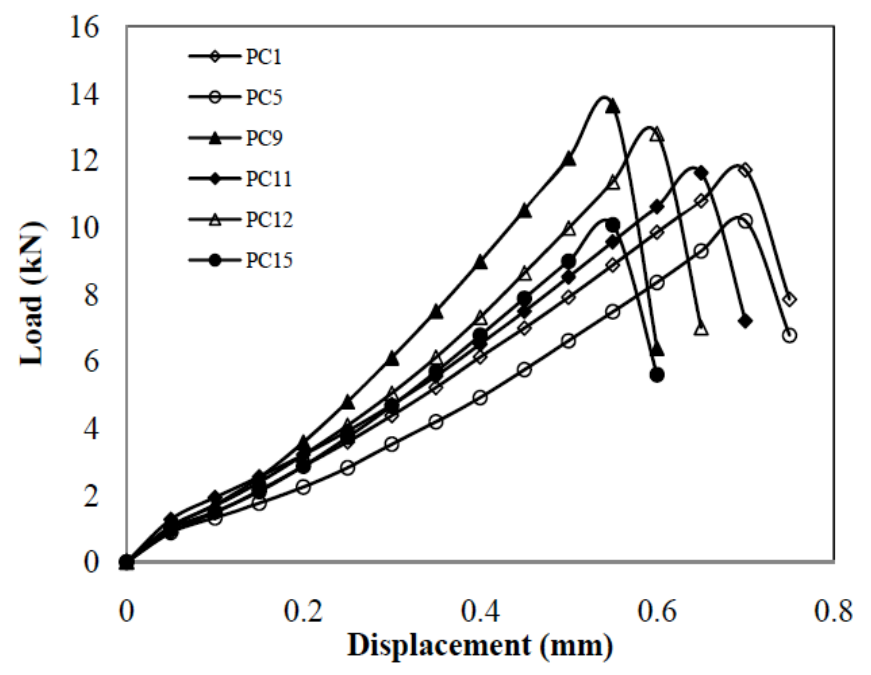

Figure 3: Load-deformation curves in flexure.

\section{Statistical Analysis of Data}

Mixture design of experiments technique has been used to optimize the number of experiments required to determine the effect of variables on mechanical properties. For each statistical combination, compressive and flexural strength was measured and suitable mathematical model as a function of the input variables were determined from regression analysis. To simplify calculations and analysis, the actual variable ranges are transformed to dimensionless coded variables with a range of $0-1$. Intermediate values are 
also transformed similarly. The variables $X_{1}, X_{2}, X_{3}$ and $\mathrm{X}_{4}$ are codified using the formula

$X_{i}=\frac{x_{i}-L_{i}}{1-L} X_{i}=$ value of component in coded form

$x_{i}=$ actual value of component

$L_{i}=$ lower limit of component in actual value

$L=$ the sum of all the lower bounds.

The mathematical relationship between independent variables and the response can be approximated by the second order polynomial:

$Y=\beta_{1} X_{1}+\beta_{2} X_{2}+\beta_{3} X_{3}+\beta_{4} X_{4}+\beta_{12} X_{1} X_{2}+\beta_{13} X_{1} X_{3}+$ $\beta_{14} X_{1} X_{4}+\beta_{23} X_{2} X_{3}+\beta_{24} X_{2} X_{4}+\beta_{34} X_{3} X_{4}+\beta_{123} X_{1} X_{2} X_{3}+$ $\beta_{234} X_{2} X_{3} X_{4}+\beta_{341} X_{3} X_{4} X_{1}+\beta_{412} X_{4} X_{1} X_{2}$

Where $\beta_{1}, \beta_{2}, \beta_{3}, \beta_{4}$ are linear coefficients, $\beta_{12}, \beta_{13}$, $\beta_{14}, \beta_{23}, \beta_{24}, \beta_{34}$ are quadratic coefficients, $\beta_{123}, \beta_{234}$, $\beta_{341}, \beta_{412}$ are quadratic coefficients, $X_{1}$ refers to coded value of resin, $X_{2}$ refers to coded value of fly ash, $X_{3}$ refers to coded value of aggregate (Type I), $X_{4}$ refers to coded value of aggregate (Type II).

The experimentally studied responses obtained after 7 days curing were analyzed statistically using Design expert software. The individual response such as compressive strength can be predicted by the regression equations given below which gives the relationship between the input variables and the response.

$Y_{c s}=33^{\star} A+63.85^{\star} B+58.46^{\star} C+56.42^{\star} D-16.36^{\star} A^{*} B$

- $18.98^{*} A^{*} C-21.02^{*} A^{*} D-0.075^{*} B^{*} C-39.38^{*} C^{*} D+$ 325.64* ${ }^{*}{ }^{*} B^{*} C+450.44^{*} A^{*} B^{*} D-1307.00^{*} B^{*} C^{*} D$

$\mathrm{Y}_{\mathrm{fs}}=17.38^{*} \mathrm{~A}+23.58^{*} \mathrm{~B}+20.88^{*} \mathrm{C}+18.94^{*} \mathrm{D}$ $22.32^{\star} A^{\star} B-18.85^{\star} A^{*} C+0.066^{*} A^{*} D-1.08^{*} B^{*} C+$ $2.76^{\star} B^{\star} D-9.05^{\star} C^{\star} D+303.32^{*} A^{*} B^{\star} D-431.08^{\star} B^{*} C^{*} D$

The above equations are based on the special cubic model suggested amongst other models such as linear, quadratic, two factor interaction, since this special cubic model fitted well with the experimental data. The fitness of the above model for individual property can be explained from the model summary statistics, and analysis of variance. Table $\mathbf{5}$ shows the experimental and predicted value of compressive and flexural strength. Regression equation is used to find predicted value.

\section{Contour Diagrams and Trace Plots}

Contour plots are response surface plots which help in identification of the type of interactions between the test variables on the response and are given in Figures 4-7. 3D contour plot helps us to visualize the effect of variables in three dimensional space. The contour plots

Table 5: Experimental and Predicted Value of Compressive and Flexural Strength

\begin{tabular}{|c|c|c|c|c|}
\hline \multirow{2}{*}{ Combination reference } & \multicolumn{2}{|c|}{ Compressive strength } & \multicolumn{2}{|c|}{ Flexural strength } \\
\hline & $\mathbf{Y}_{\text {experimental }}$ & $\mathbf{Y}_{\text {pridicted }}$ & $\mathbf{Y}_{\text {experimental }}$ & $\mathbf{Y}_{\text {pridicted }}$ \\
\hline $\mathrm{PC} 1$ & 56.51 & 56.42 & 19.06 & 18.94 \\
\hline PC2 & 40.29 & 38.65 & 15.47 & 15.17 \\
\hline PC3 & 61.09 & 61.14 & 21.91 & 21.96 \\
\hline PC4 & 44.29 & 44.34 & 14.85 & 14.90 \\
\hline PC5 & 42.73 & 42.97 & 17.68 & 17.58 \\
\hline PC6 & 41.6 & 41.84 & 14.45 & 14.35 \\
\hline PC7 & 42.7 & 41.68 & 16.67 & 17.17 \\
\hline PC8 & 58.55 & 58.46 & 20.85 & 20.88 \\
\hline PC9 & 47.85 & 47.60 & 17.69 & 17.65 \\
\hline PC10 & 52.91 & 50.68 & 18.48 & 18.59 \\
\hline PC11 & 41.24 & 40.99 & 14.31 & 14.42 \\
\hline PC12 & 63.64 & 63.85 & 23.61 & 23.58 \\
\hline PC13 & 33.09 & 33.00 & 17.35 & 17.38 \\
\hline PC14 & 65.16 & 60.14 & 22.05 & 21.95 \\
\hline PC15 & 39.71 & 39.46 & 18.22 & 18.18 \\
\hline
\end{tabular}


indicate that the interaction between the corresponding variables is significant. The optimum values are obtained at the point of intersection of the lines formed by joining the locus of the tip of the curve. In the following contour and response surface plot the aggregate type $\mathrm{II}$ is fixed to $38.9 \%$. This value of aggregate type II gives the maximum value of compressive and flexural strength in contour and response surface plot.

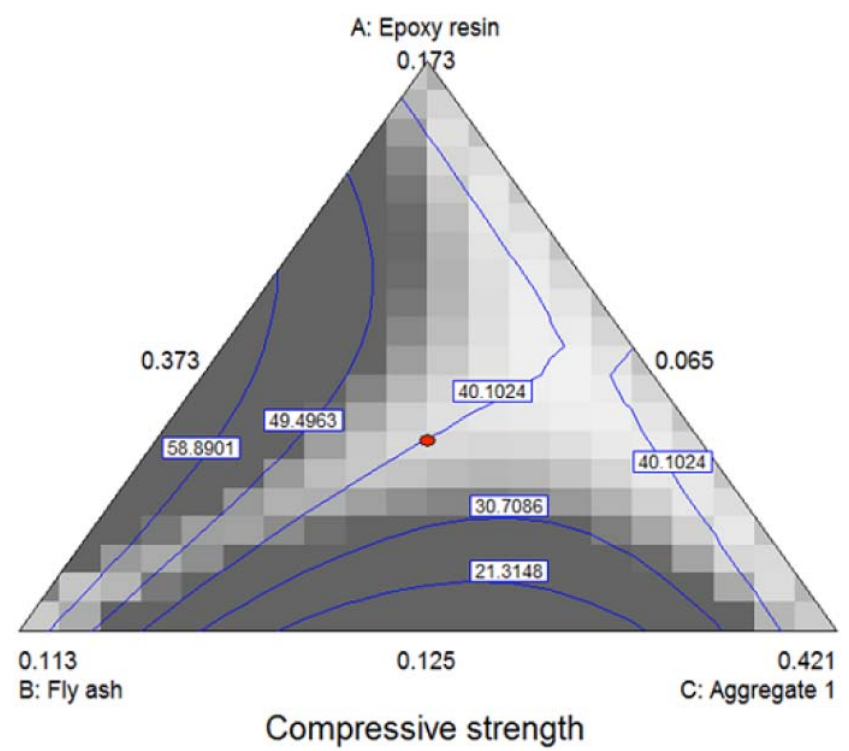

Figure 4: Contour diagram showing the effect of individual variables on compressive strength.

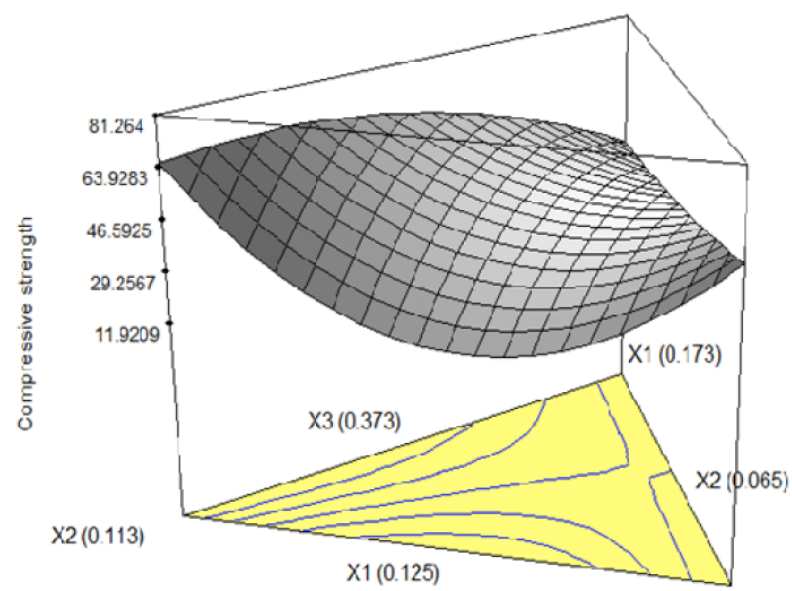

X3 (0.421)

Figure 5: Response surface plot for compressive strength.

Trace plots indicate the effect of changing each mixture component while holding all other components in a constant ratio, and are shown in Figures $\mathbf{8 , 9}$. The response is plotted while moving along an imaginary line from a reference blend to the vertex of the component being incremented. The default reference is the centroid of the design. A steep slope or curvature in

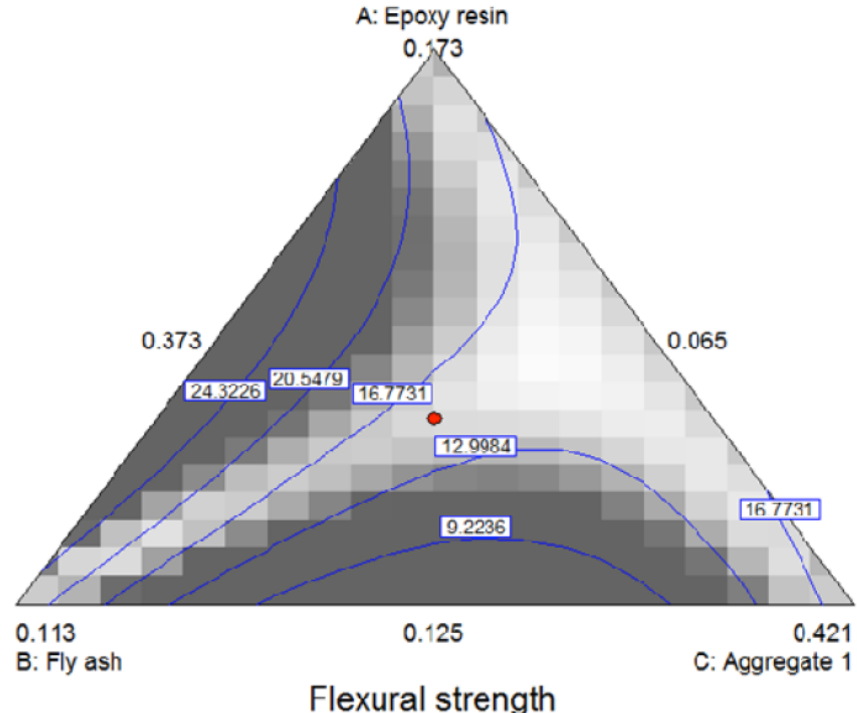

Figure 6: Contour diagram showing the effect of individual variables on flexural strength.

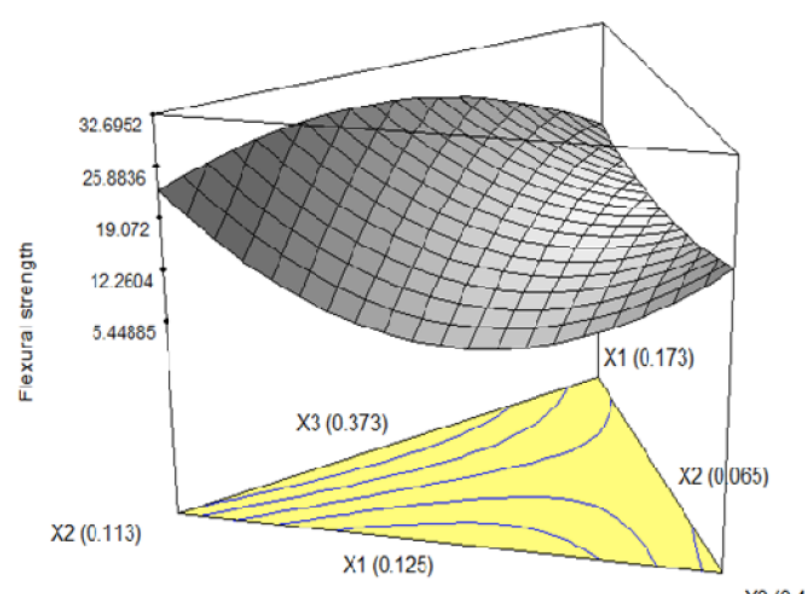

X3 (0.421)

Figure 7: Response surface plot for flexural strength.

an input variable indicates a relatively high sensitivity of response. Trace plot for Compressive strength is plotted in Figure $\mathbf{8}$ while moving along an imaginary line from a reference blend to the vertex of component being incremented. It is observed that compressive strength of polymer concrete is more sensitive to Epoxy resin content and fly ash content. Trace plot for Flexural strength is plotted as shown in Figure 9. It is observed that flexural strength of polymer concrete is also more sensitive to Epoxy resin content and fly ash content.

Table 6 shows the comparison of polymer concrete compositions for experimental maximum and predicted optimum values. It was observed that resin content corresponding to the optimum was similar that of practically studied maximum. 


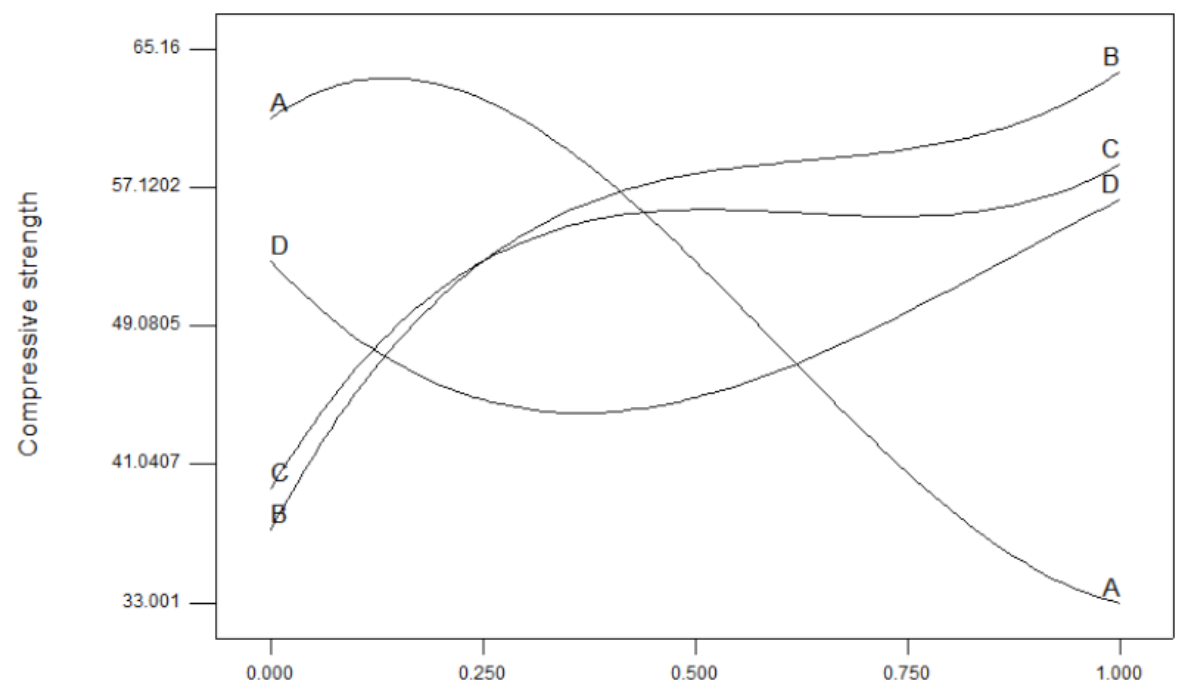

Component Range in Pseudo Values

Figure 8: Trace plot showing effect of variables on compressive strength.

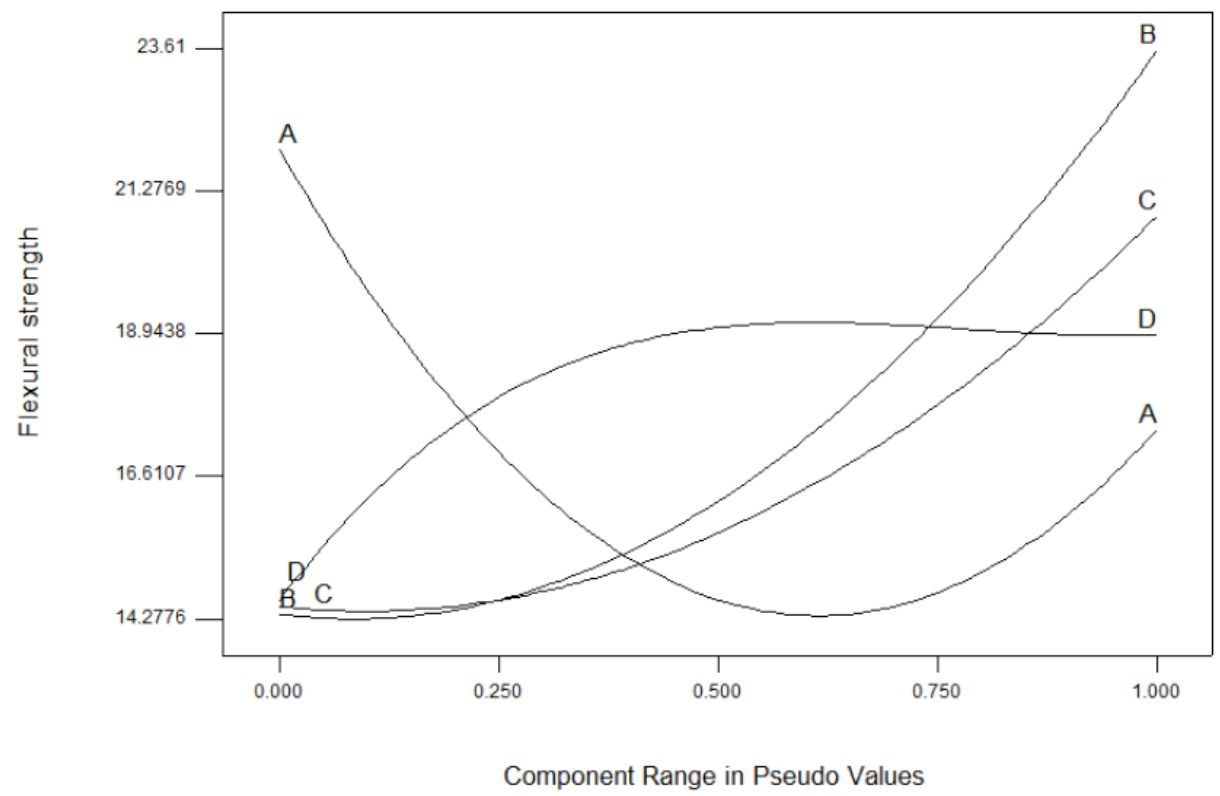

Figure 9: Trace plot showing effect of variables on Flexural strength.

Table 6: Experimental and Predicted Polymer Concrete Compositions

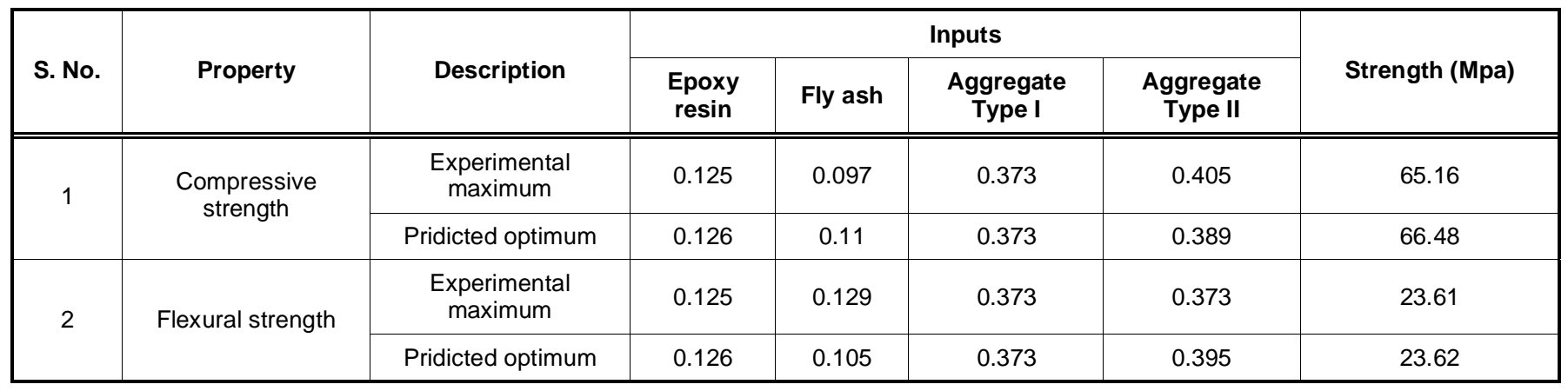




\section{CONCLUSIONS}

For the polymer concrete system studied in the present investigation, it has been observed that maximum compressive strength as well as maximum flexural strength are obtained at lowest level of resin content in the study. Regression equations have been developed for compressive as well as flexural strength and optimum values have been predicted for these. Further response surface methodology has been used to identify the type of interaction between the input variables i.e, Epoxy resin dosage, fly ash content, aggregate mix content and output variables i.e. compressive strength and flexural strength of polymer concrete. It is observed that compressive strength as well as flexural strength of polymer concrete is more sensitive to Epoxy resin content and fly ash content

\section{REFERENCES}

[1] Kirlikovali E. Polymer/Concrete composites- A Review. Polym Eng Sci 1981; 21(8): 507-9. http://dx.doi.org/10.1002/pen.760210811

[2] Fowler DW. Polymers in concrete: A vision for the 21st century. Cem Concr Compos 1999; 21: 449-52. http://dx.doi.org/10.1016/S0958-9465(99)00032-3

[3] Barbuta M, Lepadatu D. Mechanical characteristic investigation of polymer concrete using mixture design of experiment and response surface method. J Appl Sci 2008; 8(12): 2242-9.

[4] Harja M, Barbuta M, Rusu L. Obtaining and characterization of polymer concrete with fly ash. J Appl Sci 2009; 9(1): 8896.

http://dx.doi.org/10.3923/jas.2009.88.96

[5] Vipulanandan C. Characterization of Polyester Polymer and Polymer Concrete. J Mater Civ 1993; 5(1): 62-82. http://dx.doi.org/10.1061/(ASCE)0899-1561(1993)5:1(62)

[6] Maksimov RD, Jirgens L, Jansons J, Plume E. Mechanical properties of polyester polymer concrete. Mech Compos Mater 1999; 35(2): 99-103.

http://dx.doi.org/10.1007/BF02257239
[7] El-Hawary MM, Abdel-Fatteh $\mathrm{H}$. Temperature effect on the mechanical behaviour of resin concrete. Constr Build Mater 2000; 14: 317-23.

http://dx.doi.org/10.1016/S0950-0618(00)00032-5

[8] Gorninski JP, Dal Molin DC, Kazmierczak CS. Strength degradation of polymer concrete in acidic environments. Cem Concr Compos 2007; 29: 637-45. http://dx.doi.org/10.1016/j.cemconcomp.2007.04.001

[9] Mahdi F, Abbas H, Khan AA. Strength characteristics of polymer mortar and concrete using different compositions of resins derived from postconsumer PET bottles. Constr Build Mater 2010; 24: 25-36.

http://dx.doi.org/10.1016/j.conbuildmat.2009.08.006

[10] Muthukumar M, Mohan D. Studies on Furan polymer concrete. J Polym Res 2005; 12: 231-41.

http://dx.doi.org/10.1007/s10965-004-3206-7

[11] Muthukumar M, Mohan D. Studies on polymer concrete based on optimized aggregate mix proportion. Eur Polym $\mathrm{J}$ 2004; 40: 2167-77. http://dx.doi.org/10.1016/i.eurpolymj.2004.05.004

[12] Brockenbrough TW. Fibre Reinforced methacrylate polymer concrete. ACl Mater J 1982; 322-5.

[13] Griffiths R, Ball A. An assessment of the properties and degradation behaviour of glass-fibre-reinforced polyester polymer concrete. Compos Sci Technol 2000; 60: 2747-53. http://dx.doi.org/10.1016/S0266-3538(00)00147-0

[14] Sett K, Vipulanandan C. Properties of polyester polymer concrete with glass and carbon fibers. ACl Mater J 2004; 101: 30-41.

[15] Reis JML. Mechanical characterization of fiber reinforced polymer concrete. Mater Res 2005; 8(3): 357-60. http://dx.doi.org/10.1590/S1516-14392005000300023

[16] Rebeiz KS, Serhal SP, Craft AP. Properties of Polymer Concrete Using Fly Ash. J Mater Civ Eng 2004; 16: 15-9. http://dx.doi.org/10.1061/(ASCE)0899-1561(2004)16:1(15)

[17] Varughese KT, Chaturvedi BK. Fly ash as a fine aggregate in polyester based polymer concrete. Cem Concr Res 1995; 18: 105-8.

[18] Montgomery DC. Design and Analysis of Experiments. $5^{\text {th }}$ ed. John Wiley and Sons: New York 2001. 